\title{
The effects of gamification elements in e-learning platforms
}

\author{
Ruti Gafni, The Academic College of Tel Aviv Yaffo, Israel, rutigafn@mta.ac.il \\ Dafni Biran Achituv, The Academic College of Tel Aviv Yaffo, Israel, dafniba@gmail.com \\ Shimon Eidelman, The Academic College of Tel Aviv Yaffo, Israel, shimi54@gmail.com \\ Tomer Chatsky, The Academic College of Tel Aviv Yaffo, Israel, tomerchatsky@gmail.com
}

\begin{abstract}
Gamification to perform tedious tasks in an enjoyable way is used in e-learning systems. This study examines in what manner gamification elements affect the e-learning experience in software studies. Two similar e-learning platforms were developed with the aim to teach basic Linux commands, one of them including gaming elements. One group (92 participants) studied using the gamified platform, and another group (47) using a non-gamified platform. The findings show that although the exam grades were not statistically different between the groups, the motivation to learn and continue learning after this experience was higher in the group using a gamified e-learning platform.
\end{abstract}

Keywords: Gamification, gamified e-learning, badges, points, gamification elements, gamification artifacts, motivation.

\section{Introduction}

Game, according to the English Oxford Living Dictionary ("Game", n.d), is "an activity that one engages in for amusement or fun," and Play, according to the same dictionary ("Play", n.d.) is "engage in activity for enjoyment and recreation rather than a serious or practical purpose." Plays and games as serious means for achievements have been studied in different disciplines, especially in the context of work vs. play (Statler, Roos \& Victor, 2009). Gamification is the use of game design techniques and mechanisms to improve non-game activities (Deterding, Dixon, Khaled \& Nacke, 2011). Using an enjoyable context, the users are encouraged to perform tedious but substantial tasks. Gamification takes the real game-pulling features and uses them to improve the player's experience in a non-play context, such as the workplace, school, software application, or websites (Pedreira, García, Brisaboa, \& Piattini, 2015).

One of the common forms of learning using technology is e-learning, in which students acquire information, and practice the materials being studied through a computerized system (Gros \& García-Peñalvo, 2016). The potential of computer games as learning tools has generated interest in the gamification world, and caught the attention of educators interested in harnessing the capability of video games to create interesting and meaningful learning experiences (Dicheva, Dichev, Agre, \& Angelova, 2015; Hamari, 2017). Including gamification elements in the elearning system results in higher satisfaction, motivation, effectiveness, and efficiency of the 
participants, especially the Y-generation students, who grew in an age of interactive media and video games (Bosworth, 2012; Glover, 2013; Poole, Kemp, Patterson, \& Williams, 2014). Gamification is largely used in applications of languages acquisition, finding the positive effect on vocabulary development (Alemi, 2010; Meihami, Varmaghani \& Meihami, 2013), while enhancing and stimulating the learning process (Gafni, Biran-Achituv \& Rachmani, 2017). Students using computer games for learning are more active, feel more involved and more challenged than in traditional lectures (Grimley, Green, Nilsen, Thompson, \& Tomes, 2011). Moreover, gamification enables students to receive constant feedback on their progress in the classroom and provide information about their completed activity (Kapp, 2012). In order to include gamification in an e-learning environment, the system has to include gamification elements, which can appear in a variety of forms, such as points, levels, badges, medals, scoreboards and virtual goods (Dicheva et al., 2015). The role of these elements is to make users enjoy the interface in different ways, so that the user can play as much as possible, while perform tasks that would not been achieved in any other way (Hanus \& Fox, 2015).

The aim of this study is to examine in what manner adding gamification elements to an elearning platform affects the e-learning experience in software studies. In order to explore this, an experimental design with a random assignment of participants into two groups (gamified platform learning group vs. non-gamified platform group) was conducted. Two similar elearning platforms were developed, with the aim to teach basic Linux commands, one of them including some gaming elements. After concluding the learning session, the students performed an exam, in order to check the understanding of the taught topics. The same exam was performed in both platforms. Finally, the students had to complete a survey. The findings show that although the exam grades were not statistically different between the two groups, the motivation to learn and to continue learning after this experience were higher in the group using a gamified e-learning environment. The remainder of this paper is organized as follows. First, a theoretical background of gamification is provided. Then, the research questions are explained. The methodology section describes the manner this study was conducted. Thereafter, the results are displayed, and finally the discussion and conclusions are presented.

\section{Theoretical Background}

The use of gamification in order to perform non-game activities has been growing in the last decade. Researchers are still trying to decode this instrument, in order to understand the pros and cons of using elements of gamification, finding diverse and sometimes contradicting results. Statler, Roos, and Victor (2009) stated that the potential impact of "playing" work activities in organizations can benefit the organization, by involving imagination, fun, emotions and cognitive skills of the individual. Organizations cope with the apparently contradiction between productivity and efficiency, vs. creativity and deep learning goals. However, there is no conflict between these organizational goals, and they should coexist harmoniously, side by side (Kolb \& Kolb, 2010). Different aspects of gamification have been studied in recent years: 


\section{First Impression of the System}

Users' perception and evaluation of websites, applications, and information systems are determined before being used and experienced, by their first impression, which involves content, usability, and aesthetics. Thielsch, Blotenberg, and Jaron (2013) stated that aesthetics is the most important component for the first impression, while after experiencing the use of the system, content is the most important for continuing using it, especially when the users are asked to be active. Kapp (2012) included the 'game thinking' as one of the main building blocks of gamification, and stated that "using game-based mechanics, aesthetics, and game thinking to engage people, motivate action, promote learning, and solve problems" (p. 10).

\section{Gamification Elements}

A large range of gamification elements exists. These are called also gamification artifacts or mechanics. The most common are the following (Dicheva et al., 2015):

(1) Points - are used to reward users through multiple dimensions and different categories (da Rocha, Gomes, \& de Melo, 2016).

(2) Levels - indicate that the user has reached a certain goal or completed a task. In computer games, the players complete different tasks, and thus, can progress in the game. The levels are designed to challenge the players, thereby creating pleasure and a desire to continue playing the game (Goehle, 2013).

(3) Badges, trophies, and medals - express external recognition that the user has reached new levels and has succeeded in the challenges. This kind of rewards stimulate the users and their desire to complete the challenges (da Rocha et al., 2016), providing pleasure and interest (Antin \& Churchill, 2011).

(4) Ranking, leaderboards, and scoreboards - These elements show users' relative position compared to others, which are commonly used to show and manage users achievements, in order to use competition as an incentive for behavior, thus, improving motivation (Cagiltay, Ozcelik, \& Ozcelik, 2015).

(5) Virtual Goods - are nonphysical and intangible objects that can be acquired through accumulated points. Virtual goods create incentives to get more points, complete tasks, and challenges. In addition, they allow personalization of the reward according to the type of user (da Rocha et al., 2016). It is very common to use virtual currencies in various situations, including for trading products, points for raising status, and prestige (da Rocha et al., 2016).

\section{Gamification and Motivation}

Motivation is composed of processes provoking, directing, and preserving human behavior toward a particular goal. People have different needs and desires: rewards, status, achievements, self-expression, and competition (Richter, Raban, \& Rafaeli, 2015). Researchers distinct between two different kinds of motivation: intrinsic and extrinsic motivations (Levesque, 2011). Intrinsic motivation is based on internal interests and willingness to engage to a specific activity, with no external factors involved, because the specific activity is inherently interesting or enjoyable (Ryan \& Deci, 2000). According to Kolb and Kolb (2010), individuals who are 
engaged in experiential learning are intrinsically motivated. Intrinsic motivation is very important, but most of the activities people need to perform are not intrinsically motivating (Ryan \& Deci, 2000). Therefore, it is important to add some extrinsic motivations. Extrinsic motivation is based on external factors such as rewards, either tangible, or intangible (Deci, Koestner, \& Ryan, 2001). Both intrinsic and extrinsic motivations are combined in the use of gamification. There has been a significant increase in the use of game elements in non-game applications, in order to increase user engagement and motivation (da Rocha et al., 2016; Richter et al., 2015), which have different roles, for example:

(1) Prizes - tangible or intangible, implemented in points, trophies, medals, and virtual goods, are granted after certain achievements.

(2) Status and reputation - most people need feelings like fame, prestige, attention, appreciation and respect from others. To achieve this, they need to engage in certain activities. These are implemented in collecting badges, levels, ranking, profiles and leaderboards.

(3) Competition - the desire to be the winner can increase performance. High levels of motivation can be achieved implementing ranking, scoreboards and leaderboards.

The gamification of e-learning platforms has the potential to increase motivation among students by learning in new ways and enjoying tedious and boring tasks (Hanus \& Fox, 2015). To achieve this potential effectiveness, great effort is required to design, develop, and create a motivating experience (Domínguez et al., 2013). Some studies have been conducted to explore intrinsic and extrinsic motivations when using reward platforms. Some meta-analyses (Deci et al., 2001; Richter et al., 2015) suggested that rewards that are designed to increase extrinsic motivation undermine the intrinsic one. Thus, having negative impact on learners. On the one hand, awarding prizes for tasks that already have interest reduces internal motivation. On the other hand, incentives given for boring tasks have increased internal motivation (Cameron, Banko, \& Pierce, 2001). Therefore, studies recommend creating systems of gamification containing a combination of both external and internal incentives that will maintain the level of interest and long-term user engagement (Cameron et al., 2001; Ryan \& Deci, 2000).

\section{Learning Through Gamification}

Learning is a holistic and circular process, which includes experiencing, reflecting, thinking, and acting accordingly (Kolb \& Kolb, 2009). Reworking and relearning of knowledge, is achieved through experience and feedback. Learning needs time and space to be done (Kolb \& Kolb, 2010). Experiencing learning in an enjoyable and competitive way can enhance the engagement of the learner to the process, due to the feelings of pleasure, and to the stimulation to reflect (Kolb \& Kolb, 2010). Including gamification elements in the learning process can benefit the learner's experience. There have been several studies of gamification at school and universities with an emphasis on the gamification elements' influence including rewarding points and badges.

\section{Rewarding points}

The use of rewarding points affects the studying process in the following ways:

(1) Points raise internal motivation (Mekler, Brühlmann, Opwis, \& Tuch, 2013). 
(2) Because points are rewarded according to achievements, they can be perceived as providing feedback on students' progress, which is helpful and encourages continued learning (Mekler et al., 2013).

(3) Rewarding points increases the participants' involvement in learning with a software game (Li, Dong, Untch, \& Chastee, 2013). However, points given for participation instead of points for achievements, have no effect on the quality of the tasks performed (Lister, 2015).

\section{Badges}

Prior studies found that the majority of the students invested efforts in the studying activities, in order to achieve the goals imposed by levels and stages (Goehle, 2013). The use of badges has several positive aspects, such as:

(1) Encouraging user's activity and thus increasing participation (Denny, 2013; Grant \& Betts, 2013).

(2) Leveraging the motivation of the users (Haaranen, Ihantola, Hakulinen, \& Korhonen, 2014), their engagement with the system (Hakulinen, Auvinen, \& Korhonen, 2015; Luo, Yang, \& Meinel, 2015) and their achievements (Antin \& Churchill, 2011; da Rocha et al., 2016).

(3) Feeling satisfaction for completing tasks (Goehle, 2013).

In contrary, the use of badges can have other effects:

(1) If the achievements that award the badges are too difficult, they can cause frustration (Luo et al., 2015).

(2) Some students are indifferent to badges (Haaranen et al., 2014).

(3) Rewards are usually effective only in the short term. In the long term, users lose interest in rewards, affecting motivation. As long as they want to ensure long-term motivation, users should be encouraged to increase internal motivation rather than external motivation (Luo et al., 2015).

(4) Student's motivation depends on their prior knowledge: low-performing students are motivated by badges granted for their participation, while high-performing students are motivated by post-proficiency badges (Abramovich, Schunn, \& Higashi, 2013).

(5) Awarding prizes for interesting tasks, reduces internal motivation. However, incentives given for boring tasks increase internal motivation (Cameron et al., 2001).

As a result, many educational software platforms have been developed in order to create an easy, fun, and challenging way to study, using some of the mentioned gamification elements. In order for a gamification platform to work successfully, it must be design with a clear purpose and instructions, developing several ways to solve the tasks, in order to adjust to different levels of knowledge, and to include hints to guide the users (Dong et al., 2012).

\section{Research Questions}

In order to find out how gamification contributes to the study of software, three research questions were defined: 


\section{RQ1: How do gamification elements influence intrinsic and extrinsic motivation of software learners?}

In this paper, gamification elements examined are badges, points, and profile, which represents the levels of the user's progress. According to the papers reviewed in Lister (2015)'s metaanalysis, badges, points, and levels are the most common elements of gamification. Badges increase extrinsic motivation but might have both positive (Hakulinen et al., 2015; Luo et al., 2015) and negative influence on intrinsic motivation (Cameron et al., 2001; Luo et al., 2015). Points have positive influence on internal motivation (Mekler et al., 2013). As levels are designed to increase interest and enjoyment (Goehle, 2013) they are supposed to have positive influence on intrinsic motivation.

\section{RQ2: Do gamification elements enable better understanding of software studies?}

Understanding of software studies is examined both by an exam the participants performed in this research, and by data, which was collected after the participants' experienced with the elearning platform, concerning their perceived understanding of the material. Prior research shows that gamification has a stimulation effect on learners (Gafni et al., 2017). Rewards raise extrinsic motivation of learners to spend more time learning and answering more questions, without reducing their quality (Denny, 2013). According to some studies, students that get more rewards have better performances by average (da Rocha et al., 2016). On the other hand, gamified courses might show lower grades as an effect of intrinsic motivation reduction (Hanus \& Fox, 2015).

\section{RQ3: Is a gamified e-learning platform the preferred studying environment for students?}

Participants were asked to check their preference of various studying means: watching video tutorials, using gamified applications, learning with private teachers, learning from the Internet, learning in traditional face-to-face classes or by reading a book. Using an enjoyable context, the users are encouraged to perform tedious but substantial tasks (Deterding et al., 2011). However, is it the preferred means for the students? Does the experience of learning with a gamified platform and having a positive experience change the way students want to study?

\section{Methodology}

The research methodology included two stages.

Stage 1: In order to test the research hypotheses, an experimental design with a random assignment of participants into two groups (gamified platform learning group vs. non-gamified platform group) was conducted. Post-test measurement of the dependent variables: exam grades and various aspects of subjective perceptions of the learning process.

The targeted population were individuals who learnt software during their academic studies or by self -learning. Because of the specific population, for which no list of participants exists, the sample was gathered using nonprobability snowball sampling (Baltar \& Brunet, 2012; Noy, 2008). Nevertheless, the invitation to participate was not distributed in first place to individuals, or to familiar known persons, but to specific forums and groups according to the kind of 
population needed, and those relevant populations were asked to follow the invitations further. The first wave of invitations to participate was distributed through Facebook and WhatsApp social networks, to unknown students who study software in universities, academic and technology colleges, as well as to software professional groups. Those who accepted the invitation, were randomly divided into the two groups, in order to have two third of the participants performing the gamified course, and one third performing the non-gamified course.

Two similar e-learning platforms were developed, using the WIX environment (Free website builder: https://www.wix.com/), and a Linux server based on Amazon's Web Services (AWS) cloud, in order to teach basic commands in Linux operation system. Both platforms taught the same contents, and had a same exam at the end, in order to evaluate the learning results. Both groups had a concrete time framework to perform their learning process, and both use the computer as the space for learning, according to Kolb and Kolb theory (2010). The "regular" elearning platform consisted of information and explanations about the Linux commands, and examples on how to use them. The "gamified" e-learning platform included the same content as the "regular" one, but with a gamified framework, including gamification elements like advancing through levels, getting badges and points, and updating the user's profile according to the achievements (Figure 1). Each step entitled the learner to use the commands taught, in order to find passwords hidden in the Linux server. Using the found passwords, the users could advance to the next level. Using the "gamified" e-learning platform, the students go through all stages in the learning cycle of Kolb and Kolb (2009): they experienced the activity of learning in an enjoyable way, through the gamification, they received feedback, in shape of points, badges and changes in profiles, which contributed to their reflection on their learning progress, thinking about the next step they have to perform, and then deciding how to act, in order to get to the next level.

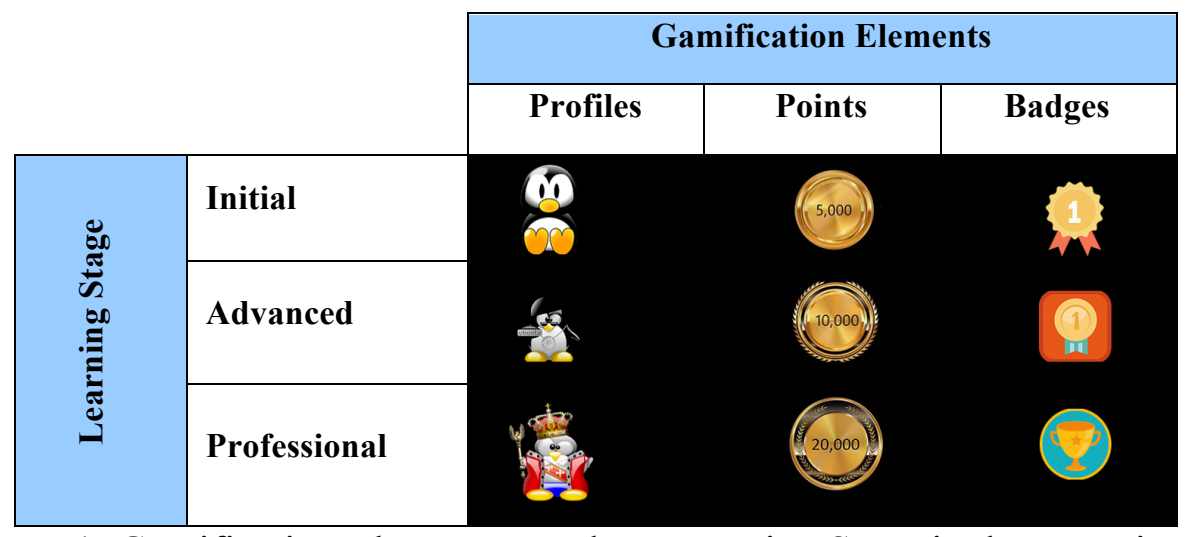

Figure 1: Gamification Elements Used vs. Learning Stage in the Experiments

After finishing the learning phase, the participants, in both platforms, were asked to take an exam, which evaluated their understanding, giving them a grade, according to the correct answers. The goal of the exam was to find whether there are differences in the understanding of the materials taught in both platforms. After finishing the exam, each participant received a survey, in order to examine the user's experience using the platform. The basis of the instrument survey was the same for both groups. The survey was composed from some basic demographic questions, some questions regarding the perception of the participants on the difficulty of the 
course and the exam, as well as the level of interest and willingness to study the subject using the application. The answers to these questions were defined using a 5-point Likert type scale, defining level of interest/difficulties/satisfaction from 1 (not at all) to 5 (very much). The third part of the survey asked for the preferred means for learning, where a list of means was displayed, and each participant could check one answer or more.

Stage 2: In order to add more in-depth understanding of using the gamification elements, the second stage focused on the participants of the gamification platform group only. The group that participated in the gamified e-learning platform had to answer a second part of the survey, in which the experience with each gamification element was examined. This survey, which was answered only by the participants who performed the gamified course, asked about their perceptions to the effects of the different gamification elements on the learning motivation. These answers to these questions were defined using a 5-point Likert type scale, from 1 - not at all to 5 - very much. All the ordinal Likert type scales were balanced (i.e. the distance between each value of the scale is the same), so it is acceptable to use the mean to represent the central tendency of the distribution, as well to perform t-tests, correlations, and other parametric statistics (Norman, 2010). Such statistics are presented in the tables of the Results section below. The surveys, elaborated using Google Forms, enabled keeping the anonymity of the participants. The responses to the survey were analyzed using IBM $^{\circledR}$ Statistical Package for Scoail Sciences $\left(\mathrm{SPSS}^{\circledR}\right)$, version 25 .

\section{Results}

Results from the experiments follow the two stages discussed above.

\section{Stage 1 results:}

The data was gathered from the surveys that the participants filled in, after using one of the elearning platforms and performing the exam. Table 1 shows the descriptive statistics of the study participants. Most of the participants in both groups were male students.

Table 1. Descriptive Statistics of the Study Participants (N=139)

\begin{tabular}{|ll|c|c|}
\hline Demographics Variable & $\begin{array}{c}\text { Gamified } \\
\text { Platform }\end{array}$ & $\begin{array}{c}\text { Non-Gamified } \\
\text { Platform }\end{array}$ \\
\hline No. of participants & & 92 & 47 \\
\hline Gender (\%) & Male & $74 \%$ & $70 \%$ \\
& Female & $26 \%$ & $30 \%$ \\
\hline Academic Level (\%) & High school & $11 \%$ & $4 \%$ \\
& Non-academic studies & $13 \%$ & $17 \%$ \\
& Undergraduate studies & $46 \%$ & $47 \%$ \\
& Graduate studies & $24 \%$ & $23 \%$ \\
& Master & $0 \%$ & $2 \%$ \\
& Other & $7 \%$ & $6 \%$ \\
\hline
\end{tabular}


In order to examine RQ2, the same exam was performed by all the participants in both groups.

Table 2. Exam and Perceived Difficulty $(\mathrm{N}=139)$

\begin{tabular}{|c|c|c|c|c|}
\hline \multirow[t]{2}{*}{ Demographics Variable } & \multicolumn{2}{|c|}{$\begin{array}{c}\text { Gamified } \\
\text { Platform }\left(\mathrm{n}_{1}=92\right)\end{array}$} & \multicolumn{2}{|c|}{$\begin{array}{l}\text { Non-Gamified } \\
\text { Platform }\left(n_{2}=49\right)\end{array}$} \\
\hline & Mean & Percentage & Mean & Percentage \\
\hline Exam grade (Out of 100) + (STD) & $85.33(11.97)$ & & $81.15(21.07)$ & \\
\hline Degree of understanding (1-5) & 3.87 & $\begin{array}{l}1-0 \% \\
2-3.3 \% \\
3-21.7 \% \\
4-56.5 \% \\
5-18.5 \%\end{array}$ & 4.00 & $\begin{array}{l}1-0 \% \\
2-4.3 \% \\
3-21.3 \% \\
4-42.6 \% \\
5-31.9 \%\end{array}$ \\
\hline Perceived difficulty of the exam (1-5) & 2.80 & $\begin{array}{l}1-3.3 \% \\
2-35.9 \% \\
3-39.1 \% \\
4-19.6 \% \\
5-2.2 \%\end{array}$ & 2.53 & $\begin{array}{l}1-6.4 \% \\
2-44.7 \% \\
3-34.0 \% \\
4-14.9 \% \\
5-0 \%\end{array}$ \\
\hline Previous knowledge in programming (1-5) & 2.65 & $\begin{array}{l}1-19.6 \% \\
2-14.1 \% \\
3-48.9 \% \\
4-16.3 \% \\
5-1.1 \%\end{array}$ & 2.49 & $\begin{array}{l}1-25.5 \% \\
2-27.7 \% \\
3-23.4 \% \\
4-19.1 \% \\
5-4.3 \%\end{array}$ \\
\hline
\end{tabular}

Table 2 summarizes the mean and standard deviation of the exam grades. Moreover, Table 2 shows the degree of understanding the learning materials and the perceived difficulty of the exam by the participants. These questions were answered using the 5-point Likert type scale for the degree of agreement by the participants (from 1 - not at all to 5 - very much). The table shows the mean, and the percentage of each variable (1-5). As can be seen in Table 1, the participants had similar background and previous knowledge. Although the exam grade of the gamified application is higher than the non-game, and its standard deviation is smaller, t-tests performed on these results show no statistical differences $(p>0.05)$ between the groups. No differences were found between the degree of understanding and the difficulty level, between the groups as well, although the non-gamified group perceived the exam as being easier. Nevertheless, the mean of the exam grade for the non-gamified group was lower (See Table 2).

Table 3. Differences Between the Platforms ( $\mathrm{N}=139)$

\begin{tabular}{|c|c|c|c|c|}
\hline Variable & $\begin{array}{c}\text { Gamified } \\
\text { Platform } \\
\left(\mathbf{n}_{1}=92\right) \\
\text { Mean (std) }\end{array}$ & $\begin{array}{c}\text { Non-Gamified } \\
\text { Platform } \\
\left(\mathbf{n}_{2}=49\right) \\
\text { Mean (std) }\end{array}$ & t-test & $\begin{array}{c}\text { p value } \\
\text { (sig.) }\end{array}$ \\
\hline First impression of the application & $4.07(0.71)$ & $3.36(1.03)$ & -4.725 & $.000 * * *$ \\
\hline Level of interest & $3.83(0.96)$ & $3.06(1.09)$ & -4.058 & $.000 * * *$ \\
\hline Desire to continue learning Linux & $3.75(0.92)$ & $2.96(1.30)$ & -4.154 & $.000 * * *$ \\
\hline Desire to learn other courses & $4.36(0.79)$ & $2.81(1.37)$ & -7.981 & $.000 * * *$ \\
\hline Feeling lack of stimulus during the studies & $0.04(0.20)$ & $0.53(0.50)$ & 8.092 & $.000 * * *$ \\
\hline
\end{tabular}

$* p<0.05, * * p<0.01, * * * p<0.001$ 
The participants were asked a number of questions in order to evaluate the effect of integration of gamification elements in the learning environment, with the purpose to understand RQ3. Ttests were performed in order to identify differences between the groups. Table 3 shows the means and standard deviations of the variables examined, as well as the t-tests of the statistical significant differences. In this analsyis, all measures including: first impression of the application, level of interest, desire to continue learning linux, desire to learn other courses, and feeling lack of stimulus during the studies were found to be significant between the two groups $(\mathrm{p}<0.001)$.

Correlations were performed between independent variable (Gamified platform: game or nongame platform) and the dependent variables - exam grades and various aspects of subjective perceptions of the learning process. Table 4 shows the correlations found. As shown, there is no correlation between the grade the participants received in the exam, and the platform, but there was a positive correlation between the level of interest in the materials and the exam grade.

Table 4. Correlation Matrix of Dependent and Independent Variables $(\mathrm{N}=139)$

\begin{tabular}{|c|c|c|c|c|c|c|c|}
\hline Variable & $\begin{array}{l}\text { Gamified } \\
\text { platform }\end{array}$ & $\begin{array}{l}\text { Exam } \\
\text { Grade }\end{array}$ & $\begin{array}{c}\text { First } \\
\text { impression } \\
\text { of the } \\
\text { application } \\
\end{array}$ & $\begin{array}{l}\text { Level of } \\
\text { interest }\end{array}$ & $\begin{array}{c}\text { Desire to } \\
\text { continue } \\
\text { learning } \\
\text { Linux } \\
\end{array}$ & $\begin{array}{l}\text { Desire to } \\
\text { learn other } \\
\text { courses }\end{array}$ & $\begin{array}{c}\text { Feeling } \\
\text { lack of } \\
\text { stimulus }\end{array}$ \\
\hline $\begin{array}{l}\text { Gamified } \\
\text { platform }\end{array}$ & - & $\begin{array}{c}0.126 \\
\text { sig } 0.138\end{array}$ & $\begin{array}{l}0.374 * * * \\
\text { sig } 0.000\end{array}$ & $\begin{array}{l}0.340^{* * * *} \\
\text { sig } 0.000\end{array}$ & $\begin{array}{l}0.334 * * * \\
\text { sig } 0.000\end{array}$ & $\begin{array}{l}0.563 * * * \\
\text { sig } 0.000\end{array}$ & $\begin{array}{c}-0.569 * * * \\
\operatorname{sig} 0.000\end{array}$ \\
\hline Exam Grade & & - & $\begin{array}{c}0.051 \\
\text { sig } 0.554 \\
\end{array}$ & $\begin{array}{l}0.298 * * * \\
\text { sig } 0.000 \\
\end{array}$ & $\begin{array}{c}0.214^{*} \\
\text { sig } 0.011 \\
\end{array}$ & $\begin{array}{c}0.132 \\
\text { sig } 0.12 \\
\end{array}$ & $\begin{array}{l}-0.225^{* *} \\
\text { sig } 0.008 \\
\end{array}$ \\
\hline $\begin{array}{l}\text { First impression } \\
\text { of the } \\
\text { application }\end{array}$ & & & - & $\begin{array}{c}0.287 * * \\
\text { sig } 0.001\end{array}$ & $\begin{array}{l}0.336^{* * *} \\
\operatorname{sig} 0.000\end{array}$ & $\begin{array}{l}0.557 * * * \\
\operatorname{sig} 0.000\end{array}$ & $\begin{array}{c}-0.378 * * * \\
\operatorname{sig} 0.000\end{array}$ \\
\hline Level of interest & & & & - & $\begin{array}{l}0.526^{* * *} * \\
\operatorname{sig} 0.000\end{array}$ & $\begin{array}{l}0.462 * * * \\
\text { sig } 0.000\end{array}$ & $\begin{array}{c}-0.342 * * * \\
\operatorname{sig} 0.000\end{array}$ \\
\hline $\begin{array}{l}\text { Desire to } \\
\text { continue } \\
\text { learning Linux } \\
\end{array}$ & & & & & - & $\begin{array}{l}0.601 * * * \\
\operatorname{sig} 0.000\end{array}$ & $\begin{array}{c}-0.426^{* * *} * \\
\operatorname{sig} 0.000\end{array}$ \\
\hline $\begin{array}{l}\text { Desire to learn } \\
\text { other courses }\end{array}$ & & & & & & - & $\begin{array}{c}-0.533 * * * \\
\operatorname{sig} 0.000 \\
\end{array}$ \\
\hline $\begin{array}{l}\text { Feeling lack of } \\
\text { stimulus }\end{array}$ & & & & & & & - \\
\hline
\end{tabular}

Gamification of the e-learning platform is positive correlated to the first impression the participant had from the platform, the level of interest, and the desire to continue learning, both the same subject and other courses. Significant correlations were found between first impression and the desire to continue learning (same subject $\&$ other courses).

The participants, after completing the study session and the exam, were asked about their preferences for ways to learn, in order to enhance the comprehension of RQ3, where the options were: watching videos, gamified applications, private teacher, searching the Internet, face-toface classroom, and reading a book. Table 5 shows the preferences of the participants. This was a multiple-choice question. Each participant could mark more than one option. This is the reason each column does not summarize to $100 \%$. As can be seen, there are some major differences between the two groups. Those who experienced a gamified platform prefer to keep learning in 
the same way (79.3\%), while those who did not experience this kind of learning, think indeed that it is a good way to study (53.1\%), but the first preference is by watching videos of tutorials $(61.7 \%)$.

Table 5. Preferred Ways to Study Among the Two Groups $(\mathrm{N}=139)$

\begin{tabular}{|l|c|c|}
\hline Preferred Ways to Study & $\begin{array}{c}\text { Gamified } \\
\text { Platform } \\
\left(\mathbf{n}_{\mathbf{1}}=\mathbf{9 2}\right)\end{array}$ & $\begin{array}{c}\text { Non-Gamified } \\
\text { Platform } \\
\left(\mathbf{n}_{\mathbf{2}}=\mathbf{4 9}\right)\end{array}$ \\
\hline Video & $36.9 \%$ & $61.7 \%$ \\
\hline Gamified application & $79.3 \%$ & $53.1 \%$ \\
\hline Private teacher & $6.5 \%$ & $25.5 \%$ \\
\hline Internet & $1.0 \%$ & $2.1 \%$ \\
\hline Face-to-face classroom & $8.7 \%$ & $23.4 \%$ \\
\hline Book & $10.9 \%$ & $12.7 \%$ \\
\hline
\end{tabular}

\section{Stage 2 results:}

The participants who learnt by using the gamified platform $\left(\mathrm{n}_{1}=92\right)$, were asked to answer an additional survey. The effects of the different gamification elements were examined, as well as their effect on motivation, in order to examine RQ1. The participants were asked to rate their motivation to finish the studies with points, badges, and profile raise, or without those elements. Table 6 presents the distributions of the participants' responses to the motivation to finish the learning session with and without each element, and the Pearson's correlations. As can be seen, Table 6. Gamification Elements Effects on Motivation $\left(\mathbf{n}_{1}=\mathbf{9 2}\right)$

\begin{tabular}{|c|c|c|c|c|c|}
\hline \multirow{3}{*}{$\begin{array}{l}\text { Gamification } \\
\text { Element }\end{array}$} & \multicolumn{2}{|c|}{ Motivation } & \multirow{2}{*}{\multicolumn{3}{|c|}{ Pearson's Correlations }} \\
\hline & with element & without element & & & \\
\hline & Percentage & Percentage & No Profile & No Points & $\begin{array}{l}\text { No } \\
\text { Badges }\end{array}$ \\
\hline Profile & $\begin{array}{l}\text { Not answered }-0 \% \\
1-0 \% \\
2-13 \% \\
3-20.7 \% \\
4-35.9 \% \\
5-30.4 \% \\
\end{array}$ & $\begin{array}{l}\text { Not answered }-0 \% \\
1-8.7 \% \\
2-25 \% \\
3-25 \% \\
4-31.5 \% \\
5-9.8 \% \\
\end{array}$ & $\begin{array}{l}-0.401^{* * *} \\
\text { Sig } 0.000\end{array}$ & & \\
\hline Points & $\begin{array}{l}\text { Not answered }-15.2 \% \\
1-2.2 \% \\
2-6.5 \% \\
3-29.3 \% \\
4-33.7 \% \\
5-13 \%\end{array}$ & $\begin{array}{l}\text { Not answered }-12 \% \\
1-2.2 \% \\
2-23.9 \% \\
3-28.3 \% \\
4-21.7 \% \\
5-12 \%\end{array}$ & & $\begin{array}{l}-0.498^{* * *} \\
\text { Sig } 0.000\end{array}$ & \\
\hline Badges & $\begin{array}{l}\text { Not answered }-5.4 \% \\
1-1.1 \% \\
2-13 \% \\
3-37 \% \\
4-31.5 \% \\
5-12 \%\end{array}$ & $\begin{array}{l}\text { Not answered }-4.3 \% \\
1-3.3 \% \\
2-32.6 \% \\
3-25 \% \\
4-27.2 \% \\
5-7.6 \%\end{array}$ & & & $\begin{array}{l}-0.384 * * * \\
\text { Sig } 0.000\end{array}$ \\
\hline
\end{tabular}


there is a moderate negative correlation for all three elements. Moreover, some other correlations were computed, and found that intrinsic motivation correlates positively with level of understanding $(0.233$, sig $0.026, \mathrm{p}<0.05)$, and desire to learn more courses $(0.602$, sig 0.000 , $\mathrm{p}<0.001)$ and negatively with receiving points $(-0.237$, sig $0.023, \mathrm{p}<0.05)$. Extrinsic motivation correlates positively with level of interest $(.225, \operatorname{sig}=.031, \mathrm{p}<0.05)$, updating the users' profile $(0.280$, sig $0.007, p<0.01)$ and receiving points $(0.265$, sig $0.011, p<0.05)$. The participants were asked to define which is the best reward. Their answers included: $53.3 \%$ prefer the profile updates, $27.2 \%$ prefer getting points, $14.1 \%$ prefer receiving badges, and $5.4 \%$ prefer other rewards, like tangible rewards.

\section{Discussion}

The participants were randomly divided into two groups, each one using a different e-learning platform to study the same material of basic commands in Linux operation system. One group used a gamified e-learning platform, which included gamification elements such as levels, profile updates, as well as rewards in form of badges and points. The second group used a nongamified e-learning platform. All participants pass the same exam after learning the material, in order to evaluate the learning results. Participants in both groups came from similar background, with similar previous knowledge (as shown in Table 1), and learnt the same material, in different ways. There were no statistical differences between the groups, neither in their level of understanding, nor in the difficulty the participants perceived in the exam. Moreover, this is reflected in the exam grades, which were similar, and t-tests did not find statistical differences between the groups (as shown in Table 2). Thus, according to this study, it can be said that gamification elements do not enable better understanding, answering RQ2. The fact that both groups succeeded in a similar way, can be explained by having a similar level of intrinsic motivation to learn this subject. Although the exam grades in both groups were similar, the gamification of the e-learning platform affected the participants in other ways, increasing their motivation. Both groups had a concrete time framework to perform their learning process, and both use the computer as the space for learning, according to Kolb and Kolb theory (2010). However, the group who used the gamified platform "played" to learn, competing with themselves in order to receive the awards: points, badges and profile changes, which constituted a feedback on their performance, helped them to reflect and think to their next action. In this case, using gamification elements leverage the extrinsic motivation. Their increased motivation is expressed by arising their willingness to keep learning more material of subject, to learn other courses in the same way, and their preferred ways to study. Similar findings were reported in previous research (Attali, \& Arieli-Attali, 2015), but are different from others, in which both motivation and exam grades were higher in gamified studies (Cagiltay et al., 2015), or others, that stated that exam grades were lower for the gamified experience (Hanus \& Fox, 2015). Tables 3 and 4 show that participants of the gamification group scored highly the first impression of the platform and the level of interest they found in learning this course, and they felt that they had enough stimulus during their studies. First impression is a major influence factor to enhance engagement (Thielsch et al., 2013). Joyful experiences during learning activities, encourage leveraging the responsibility of the student to excel according to his own standards. The student's enjoyment derives from both the process and the results (Kolb \& Kolb, 
2010). All these brings to more motivation for studying, as was demonstrated by correlations with the variables of desiring to expand knowledge in the course's subject, and to learn other courses in the same way. As shown in Table 6, the gamification elements help leveraging the motivation to keep studying. These results, answering RQ1, conform to most of previous studies (Attali, \& Arieli-Attali, 2015; Cagiltay et al., 2015; Kolb \& Kolb, 2010, Li et al., 2013; Richter et al., 2015), but do not suit others (Hanus \& Fox, 2015). Moreover, the experience of learning a gamified course changed the way people want to study. A significant difference in these preferences was found (see Table 5), between those who experienced an enjoyable way to study with the gamified platform and those who did not. Using games for studying was chosen by both groups, but the rate was higher in those who experienced the gamified course $(79.3 \%$ in the game group, $53.1 \%$ in the non-game group). Learning by using a video tutorial was the preference of the non-game group (61.7\%), while the game-group scored it in the second place with a much lower rate $(36.9 \%)$. Participants who did not experience the gamified e-learning platform were also willing to study with a private teacher $(25.5 \%)$ and in a face-to-face regular classroom (23.4\%), while only few participants of the gamified platform chose these means for learning. Thus, it can be said that the experience of learning with a gamified platform changed the means in which students prefer to study, answering RQ3. The difference between gamified platforms and the other ways of studying can be related to the active role of the student and degree of interaction. The other forms of learning are characterized by a more passive behavior of the participant. The preferable gamifications elements found in this study were: 53.3\% prefered profile updates, $27.2 \%$ prefered getting points, $14.1 \%$ prefered receiving badges, and $5.4 \%$ prefered other rewards, like tangible rewards. Hsu, Chang, and Lee (2013) defined the top 10 attractive gamification features, out of which the gamification elements are: badges $\left(4^{\text {th }}\right.$ place $)$, points $\left(7^{\text {th }}\right.$ place $)$, and gifts $\left(10^{\text {th }}\right.$ place $)$.

\section{Conclusions and Practical Implications}

The results show that the use of gamification does not affect the exam grades (RQ2), but does affect the willingness to study in an enjoyable way (RQ3). Using a gamified e-learning platform transforms the process of learning into an active process, more than any other way of learning. This active process, when accompanied with feedback and rewards, increases the motivation of the participants (RQ1). This can help educators to choose better means when long or boring tasks have to be performed. These conclusions can be adopted by teachers preparing online courses (for example Massively Open Online Courses (MOOCS)), which are known for very high drop-offs. There is no need to change the whole course to a game, but it is enough to incorporate some gamification elements, such as points or badges, in order to leverage the motivation to finish the course.

\section{Limitations and Further Research}

This study was based on an experiment to teach basic commands in Linux operation system, in two different groups, one using a gamified e-learning platform, and the second with a nongamified one. Both platforms taught the same contents, and had the same exam at the end, in order to evaluate the learning results. The e-learning material consisted in just one lesson of the 
course. Maybe, performing the experiment during the whole course could give more complete and accurate information, examining also if there are changes in the perceptions of the students, from the beginning of the course until its end. This can be performed in a future research. Moreover, the results of the experiment were measured using an exam and a survey, which measured the perceived opinions and feelings of the participants. In next experiments, it is interesting to insert measurements into the e-learning platforms, in order to measure also the direct use and real activity, and performance measures of the participants. In addition, the sample of participants in this study was gathered using a nonprobability method. Future research should be performed using a statistical sample.

\section{References}

Abramovich, S., Schunn, C., \& Higashi, R. (2013). Are badges useful in education?: It depends upon the type of badge and expertise of learner. Educational Technology Research and Development, 61(2), 217 - 232.

Alemi, M. (2010). Educational games as a vehicle to teaching vocabulary. Modern Journal of Applied Linguistics, 2(6), 425-438.

Antin, J., \& Churchill, E. F. (2011, May). Badges in social media: A social psychological perspective. In CHI 2011 Gamification Workshop Proceedings (pp. 1-4). New York, NY: ACM.

Attali, Y., \& Arieli-Attali, M. (2015). Gamification in assessment: Do points affect test performance? Computers \& Education, 83, 57-63.

Baltar, F., \& Brunet, I. (2012). Social research 2.0: Virtual snowball sampling method using Facebook. Internet Research, 22(1), 2012, 57-74.

Bosworth, A. (2012). Keas: developing a successful game-based employee wellness program. Games for Health: Research, Development, and Clinical Applications, 1(3), 189-191.

Cagiltay, N. E., Ozcelik, E., \& Ozcelik, N. S. (2015). The effect of competition on learning in games. Computers \& Education, 87, 35-41.

Cameron, J., Banko, K. M., \& Pierce, W. D. (2001). Pervasive negative effects of rewards on intrinsic motivation: The myth continues. The Behavior Analyst, 24(1), 1-44.

da Rocha Seixas, L., Gomes, A. S., \& de Melo Filho, I. J. (2016). Effectiveness of gamification in the engagement of students. Computers in Human Behavior, 58, 48-63.

Deci, E. L., Koestner, R., \& Ryan, R. M. (2001). Extrinsic rewards and intrinsic motivation in education: reconsidered once again. Review of Educational Research, 71, 1-27

Denny, P. (2013). The effect of virtual achievements on student engagement. In Proceedings of the SIGCHI conference on human factors in computing systems, pp. 763-772. ACM

Deterding, S., Dixon, D., Khaled, R., \& Nacke, L. (2011). From game design elements to gamefulness: Defining "gamification". Proceedings of the 15th International Academic MindTrek Conference: Envisioning Future Media Environments, 9-15. ACM. 
Dicheva, D., Dichev, C., Agre, G., \& Angelova, G. (2015). Gamification in education: a systematic mapping study. Journal of Educational Technology \& Society, 18(3), 75-89.

Domínguez, A., Saenz-De-Navarrete, J., De-Marcos, L., FernáNdez-Sanz, L., PagéS, C., \& MartíNez-HerráIz, J. J. (2013). Gamifying learning experiences: Practical implications and outcomes. Computers \& Education, 63, 380-392.

Dong, T., Dontcheva, M., Joseph, D., Karahalios, K., Newman, M., \& Ackerman, M. (2012, May). Discovery-based games for learning software. In Proceedings of the SIGCHI Conference on Human Factors in Computing Systems, pp. 2083-2086. ACM.

Game [Def. 1]. (n.d.) In English Oxford Living Dictionary. Retrieved: from: https://en.oxforddictionaries.com/definition/game

Gafni, R., Biran Achituv, D. \& Rahmani, G. J. (2017). Learning foreign languages using mobile applications. Journal of Information Technology Education: Research (JITE:Research), 16, 301-317.

Glover, I. (2013). Play as you learn: Gamification as a technique for motivating learners. In J. Herrington, et al. (Eds.), Proceedings of world Conference on educational Multimedia, Hypermedia and Telecommunications (pp. 1999-2008). Chesapeake, VA: AACE.

Goehle, G. (2013). Gamification and web-based homework. Primus, 23(3), 234-246.

Grant, S., \& Betts, B. (2013). Encouraging user behaviour with achievements: an empirical study. In Mining Software Repositories (MSR), 2013 10th IEEE Working Conference on, pp. 65-68. IEEE.

Grimley, M., Green, R., Nilsen, T., Thompson, D., \& Tomes, R. (2011). Using computer games for instruction: The student experience. Active Learning in Higher Education, 12(1), 45-56.

Gros, B., \& García-Peñalvo, F. J. (2016). Future trends in the design strategies and technological affordances of e-learning. Learning, Design, and Technology: An International Compendium of Theory, Research, Practice, and Policy, 1-23.

Hakulinen, L., Auvinen, T., \& Korhonen, A. (2015). The effect of achievement badges on students' behavior: An empirical study in a university-level computer science course. International Journal of Emerging Technologies in Learning, 10(1), 18-29.

Haaranen, L., Ihantola, P., Hakulinen, L., \& Korhonen, A. (2014). How (not) to introduce badges in online exercises. SIGCSE '14 Proceedings of the 45th ACM technical symposium on Computer science education, 33 - 38. doi: 10.1145/2538862.2538921

Hamari, J. (2017). Do badges increase user activity? A field experiment on the effects of gamification. Computers in human behavior, 71, 469-478.

Hanus, M. D., \& Fox, J. (2015). Assessing the effects of gamification in the classroom: A longitudinal study on intrinsic motivation, social comparison, satisfaction, effort, and academic performance. Computers \& Education, 80, 152-161.

Hsu, S. H., Chang, J. W., \& Lee, C. C. (2013). Designing attractive gamification features for collaborative storytelling websites. Cyberpsychology, Behavior, and Social Networking, 
$16(6), 428-435$.

Kapp, K. M. (2012). The gamification of learning and instruction: Game-based methods and strategies for training and education. John Wiley \& Sons.

Kolb, A. Y., \& Kolb, D. A. (2009). The learning way: Meta-cognitive aspects of experiential learning. Simulation \& Gaming, 40(3), 297-327.

Kolb, A. Y., \& Kolb, D. A. (2010). Learning to play, playing to learn: A case study of a ludic learning space. Journal of Organizational Change Management, 23(1), 26-50.

Levesque R. J. R. (2011). Intrinsic and extrinsic motivation. In: Levesque R. J. R. (eds) Encyclopedia of Adolescence. New York, NY: Springer.

Li, C., Dong, Z., Untch, R. H., \& Chasteen, M. (2013). Engaging computer science students through gamification in an online social network based collaborative learning environment. International Journal of Information and Education Technology, 3(1), 72-77.

Lister, M. C. (2015). Gamification: The effect on student motivation and performance at the post-secondary level. Issues and Trends in Educational Technology, 3(2), 1-22.

Luo, S., Yang, H., \& Meinel, C. (2015, May). Reward-based Intermittent Reinforcement in Gamification for E-learning. In CSEDU (1), pp. 177-184.

Meihami, B., Varmaghani, Z., \& Meihami, H. (2013). Call in the form of simulation games: Teaching english vocabulary and pronunciation through sims. International Letters of Social and Humanistic Sciences, 8, 57-65.

Mekler, E. D., Brühlmann, F., Opwis, K., \& Tuch, A. N. (2013). Disassembling gamification: the effects of points and meaning on user motivation and performance. In $\mathrm{CHI}^{\prime} 13$ extended abstracts on human factors in computing systems, pp. 1137-1142. ACM.

Norman, G. (2010). Likert scales, levels of measurement and the "laws" of statistics. Advances in health sciences education, 15(5), 625-632.

Noy, C. (2008). Sampling knowledge: The hermeneutics of snowball sampling in qualitative research. International Journal of Social Research Methodology, 11(4), 327-344.

Pedreira, O., García, F., Brisaboa, N., \& Piattini, M. (2015). Gamification in software engineering-A systematic mapping. Information and Software Technology, 57, 157-168.

Play [Def. 1]. (n.d.) In English Oxford Living Dictionary. Retrieved: from: https://en.oxforddictionaries.com/definition/play

Poole, S. M., Kemp, E., Patterson, L., \& Williams, K. (2014). Get your head in the game: Using gamification in business education to connect with Generation Y. Journal for Excellence in Business Education, 3(2), 1-9.

Richter, G., Raban, D. R., \& Rafaeli, S. (2015). Studying gamification: the effect of rewards and incentives on motivation. In Gamification in education and business (pp. 21-46). Springer International Publishing.

Ryan, R. M., \& Deci, E. L. (2000). Intrinsic and extrinsic motivations: Classic definitions and 
new directions. Contemporary educational psychology, 25(1), 54-67.

Statler, M., Roos, J., \& Victor, B. (2009). Ain't misbehavin': Taking play seriously in organizations. Journal of Change Management, 9(1), 87-107.

Thielsch, M. T., Blotenberg, I., \& Jaron, R. (2013). User evaluation of websites: From first impression to recommendation. Interacting with Computers, 26(1), 89-102.

\section{Authors' Biographies}

Ruti Gafni is the Head of the Information Systems BSc program at The Academic College of Tel Aviv Yaffo. She holds a Ph.D. from Bar-Ilan University, Israel (in the Business Administration School), focusing on Information Systems, an M.Sc. from Tel Aviv University and a BA (Cum Laude) in Economics and Computer Science from Bar-Ilan University. She has more than 40 years of practical experience as Project Manager and Analyst of information systems.

Dafni Biran Achituv teaches in the Information Systems BSc program at The Academic College of Tel Aviv Yaffo. She holds an MA in Organizational Consulting and Development (summa cum laude) and a BA in Math-ematics, Computer Science and Psychology. She has over 30 years of practical experience as a Project Manager and Information Systems Analyst.

Shimon Eidelman is a third-year student in the Information Systems BSc program at The Academic College of Tel Aviv Yaffo. He works as a Project Manager at a software developing company and has experience in various fields of IT. He is interested about the combination of Education, Technology and User Experience.

Tomer Chatsky is a third-year student in the Information Systems BSc program at The Academic College of Tel Aviv Yaffo. He works as a Network Operation Center Engineer. He is interested in Online Education and Gamification. 